\title{
SELLO ARQUEOLÓGICO SOBRE GRABADOS EN LA MESETA DEL GUITARRA (SANTA CRUZ-ARGENTINA)
}

\author{
ANAHI REa, GISELA CASSIODORO ${ }^{b}$, FRANCISCO GUICHÓN $^{c}, J^{2}$ GSEINA FLORES CONI ${ }^{d}$, \\ JUAN DELLEPIANE ${ }^{e} \&$ RAFAEL GOÑI ${ }^{\dagger}$
}

\begin{abstract}
RESUMEN
La posibilidad de asignar una cronología a las representaciones rupestres efectuadas a través de la técnica del grabado es objeto de discusión desde los inicios de la arqueología patagónica. En esta nota se presenta información que permite ampliar dicha problemática al caracterizar un sello arqueológico sobre grabados registrado en el sitio Cañadón Guitarra 3 localizado en la meseta del lago Guitarra (provincia de Santa Cruz, Argentina). Se describen los motivos grabados y su asociación con la tecnología y fechados de la excavación. La cronología absoluta establece una fecha mínima de ejecución hace 1.200 años AP. De esta manera, el sello arqueológico y las evidencias asociadas sugieren una asignación temporal de los motivos aquí discutidos acotada al Holoceno medio y al Holoceno tardío inicial. De este modo, esta información también contribuye, en distintas escalas, al conocimiento del proceso de poblamiento humano en las mesetas altas de Santa Cruz.
\end{abstract}

PALABRAS CLAVES: motivos grabados, cronología, mesetas altas.

\section{ARCHAEOLOGICAL SEAL OVER ENGRAVED MOTIFS IN THE GUITARRA PLATEAU (SANTA CRUZ- ARGENTINA)}

\footnotetext{
ABSTRACT

Engravings' chronology has been subject of numerous discussions since the beginning of archaeology in Patagonia. This paper presents information that broadens this issue as it describes an archaeological seal over engraved motifs documented in site CG3 located in the Guitarra Plateau (Santa Cruz province, Argentina). The engraved motifs are described as well as their association with technology and radiocarbon dates from the excavation. Absolute dating establishes a minimum execution date of 1.200 years BP. Thus, the archaeological seal and the related evidences suggest that the motifs here

a CONICET-UBA-INAPL. 3 de febrero 1378 (CP 1426), Ciudad Autónoma de Buenos Aires, Argentina. anahire1@gmail.com

b CONICET-UBA-INAPL. gcassio@hotmail.com

c CONICET-INAPL.guichonf@hotmail.com

d CONICET-INAPL.coquequina@yahoo.com.ar

e CONICET-INAPL.juandelle09@hotmail.com

f INAPL-UBA.rafaelagustingoni@gmail.com
} 
discussed are circumscribed to the middle Holocene and the beginning of the late Holocene. Therefore, this information contributes, in different scales, to expand our knowledge of the human peopling process in Santa Cruz's high plateaux.

KEY WORDS: engravings, chronology, high plateau.

\section{INTRODUCCIÓN}

En numerosos sitios de Patagonia centromeridional se han registrado representaciones rupestres realizadas mediante la técnica del grabado. Se han destacado las dificultades que se enfrentan cuando se discute su asignación cronológica. No obstante, las similitudes observadas en la morfología de los motivos en una escala espacial amplia han llevado a que algunos autores consideren que las mismas datarían de un mismo lapso temporal (ver, por ejemplo, Gradin, 1983). Para establecer su secuencia de ejecución la mayor parte de los trabajos consideran las superposiciones y los grados de pátina de estos motivos (Carden, 2008; Durán, 1983-85; Gradin, 1983, 2003; Re, 2010, entre otros). En particular, su cronología ha sido evaluada principalmente a partir de su asociación con registro arqueológico próximo, que incluye fechados y tecnología con temporalidad asignada. Otro indicador utilizado ha sido la presencia de similitudes con motivos de otras regiones cercanas donde se definieron secuencias más completas.

Hasta el momento solo se disponía de dos casos en Patagonia central y meridional donde se observa una asociación directa con depósitos arqueológicos datados que permiten ajustar la cronología de los grabados, si bien no se tratan de sellos arqueológicos propiamente dichos ya que los sedimentos no cubren los motivos rupestres. En el sitio de Piedra Museo en el Macizo del Deseado (Santa Cruz) se dató en ca. 7.500 años AP una capa subyacente a un bloque con grabados, lo que indica una fecha máxima para la realización de los mismos (Carden, 2008). De esta manera, se pudo afirmar que el bloque estuvo disponible para grabar con posterioridad a ese momento. Por otra parte, el ejemplo más conocido es el Alero de las Manos Pintadas, ubicado en el sur de la provincia de Chubut, donde se pudo acotar la ejecución de motivos grabados a un momento posterior a los 2.600 años AP, a partir del fechado de un derrumbe que hizo disponible la superficie donde se ejecutaron los mismos (Gradin, 1973; Gradin \& Aschero, 1978). Por su parte, los únicos casos de sellos arqueológicos sobre grabados en Patagonia habían sido registrados en Neuquén y Río Negro, otorgándoles fechas mínimas de realización entre 2.200 y 2.800 años AP con un caso excepcional previo a 9.000 años AP (Crivelli, 2006).

A partir de la suma de todos estos indicadores, la mayoría de los investigadores ha sugerido que los grabados de Patagonia centromeridional habrían sido realizados durante el Holoceno tardío (últimos 2.500 años) (ver Durán, 1983-85; Gradin, 1973, 1983, 2003; Schobinger \& Gradin, 1985). No obstante, cabe destacar que su secuencia de ejecución y particularmente su cronología ha sido establecida hasta el momento solo por medios relativos.

Recientes investigaciones en las mesetas altas del centro-oeste de la provincia de Santa Cruz han permitido complejizar esta tendencia temporal, a partir del uso de estos mismos indicadores. Así, se ha propuesto que la elaboración de los motivos grabados en esa área se habría iniciado en el Holoceno medio (ca. 5.000 años AP) con un aumento en la frecuencia y variabilidad hacia momentos tardíos (Re, 2010; Re \& Guichón, 2014, entre otros).

En este trabajo se aporta nueva información a la discusión sobre la cronología de los grabados de Patagonia centro-meridional. Particularmente, se describe un sello arqueológico sobre motivos grabados en esta macro-región localizado en el sitio Cañadón Guitarra 3 (CG3) en la meseta del lago Guitarra. En éste se registró un caso único de depósitos arqueológicos datados dispuestos sobre motivos grabados.

\section{CARACTERIZACIÓN DEL SITIO}

El sitio CG3 se encuentra ubicado en la meseta del lago Guitarra (centro-oeste de la provincia de Santa Cruz) (Fig. 1). Particularmente, se localiza en la margen sur del Cañadón Guitarra 
por el cual corre el río homónimo, actualmente seco, que en momentos de niveles mayores del lago Guitarra discurre con sentido oeste-este desembocando en la laguna del Asador (Goñi et al. 2010). El sitio se encuentra en una barda basáltica con forma de herradura orientada al norte que presenta una extensión superior a los $200 \mathrm{~m}$ y una altura promedio de $4 \mathrm{~m}$, con sectores de mayor altitud que alcanzan los $10 \mathrm{~m}$. El sitio ofrece la mejor protección contra el viento y la nieve de la meseta. Con respecto a la evidencia arqueológica, se destaca la presencia de material lítico, tanto en superficie como en estratigrafía, cerámica en superficie y también, manifestaciones rupestres (Cassiodoro et al. 2013; Re \& Guichón, 2013). Al igual que en otros sectores del cañadón, el registro arqueofaunístico se encuentra ausente (Goñi et al. 2010).

Dentro de la meseta del Guitarra este sitio sobresale en dos aspectos. Por un lado, es el que presenta la mayor cantidad $(\mathrm{N}=133)$ y diversidad de motivos, así como de técnicas de grabado (Re, 2010; Re \& Guichón, 2013). Por otra parte, se destaca por ser el único con cronologías tanto del Holoceno tardío como del medio (Cassiodoro et al. 2013; Goñi et al. 2010).

Los motivos rupestres de CG3 fueron sistematizados en 21 unidades topográficas (UT), encontrándose la mayor concentración en un sector de $60 \mathrm{~m}$ de largo aproximadamente, que se extiende desde la UT1 a la UT18. Se reconocieron 19 tipos de motivos, 14 abstractos y 5 figurativos (Re, 2010; Re \& Guichón, 2013). Entre los primeros se destacan los motivos de trazo, línea recta y círculo como los más abundantes, aunque también se observan líneas curvas, semicírculos, caóticos y líneas sinuosas, entre otros. En los figurativos se cuentan escasos ejemplos de huellas de felino, tridígitos, huella humana, figura de guanaco del grupo de diseños 1 (sensu Re, 2010) y una escena de caza (huellas humanas y de guanacos asociados a una figura de este animal de grupo de diseños 2 , sensu ib.). Todos los motivos fueron grabados, principalmente mediante la técnica del picado (89\%). En cuanto a las pátinas, predomina el grado 3 o menos desarrollada con el $70 \%$ de los motivos, seguida por la intermedia (grado 2) y escasos ejemplos de la más desarrollada o pátina de grado 1. La diversidad de pátinas y la cantidad de superposiciones evidencian un uso recurrente de este espacio (Re \& Guichón, 2013).

En principio los motivos de CG3 siguen las tendencias temporales propuestas para los grabados de las mesetas altas en general (Re, 2010; Re \& Guichón, 2013, entre otros). Así, se pueden diferenciar al menos dos momentos de producción. En primer lugar, se ha propuesto durante el Holoceno medio la representación de siluetas de guanacos del grupo de diseños 1 en conjunto con una serie de motivos abstractos como líneas rectas paralelas, círculos y líneas sinuosas, entre otros. Por otra parte, durante el Holoceno tardío, se observa una mayor diversidad de motivos, tanto entre los figurativos como los abstractos. Los primeros corresponden a una variedad de pisadas (tridígitos, huellas de felino, huellas humanas, etc.) así como a figuras de guanacos (grupo de diseños 2) y escenas de caza, entre otros. En cuanto a los motivos abstractos, la variedad de tipos aumenta y sobresalen semicírculos, trazos, líneas curvas, además de los ya nombrados para el primer momento. Recientemente se ha ahondado en la caracterización de los grabados del Holoceno tardío en las mesetas altas y se ha postulado que pueden identificarse motivos de tres momentos distintos: Holoceno tardío inicial, final $y$ postcontacto (Re \& Guichón, 2014). A los fines de este trabajo cabe destacar que particularmente en el caso de las pisadas se ha planteado que los tridígitos posiblemente comenzaran a ejecutarse durante el Holoceno tardío inicial mientras que las restantes huellas serían posteriores.

En función de la densidad de las manifestaciones rupestres y de las condiciones diferenciales de reparo, se establecieron dos sectores de excavación vinculados a la UT1 y a la UT14 (Cassiodoro et al. 2013). En este trabajo se detalla esta última UT dado que a partir de la excavación realizada, en ella se documentaron los grabados tapados por sedimentos arqueológicos. Colindante a esta UT se plantearon dos cuadrículas de $1 \mathrm{~m}$ por $1 \mathrm{~m}$ con niveles artificiales de $5 \mathrm{~cm}$. Se excavaron 13 niveles completos en una de ellas y 21 en la otra. Previo a la excavación, la UT14 presentaba 7 motivos realizados mediante picado, reconociéndose cuatro líneas sinuosas de 


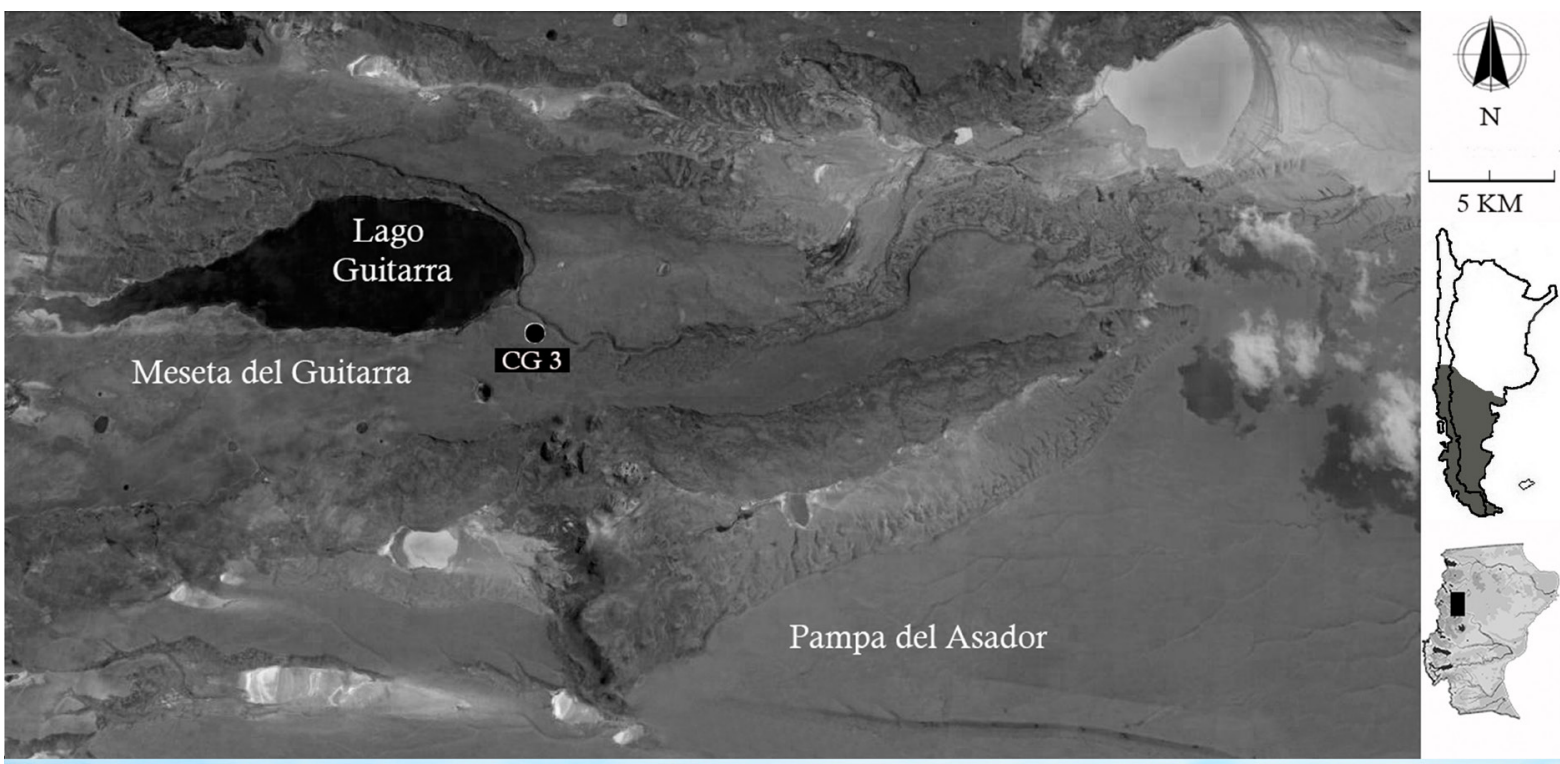

UT 14

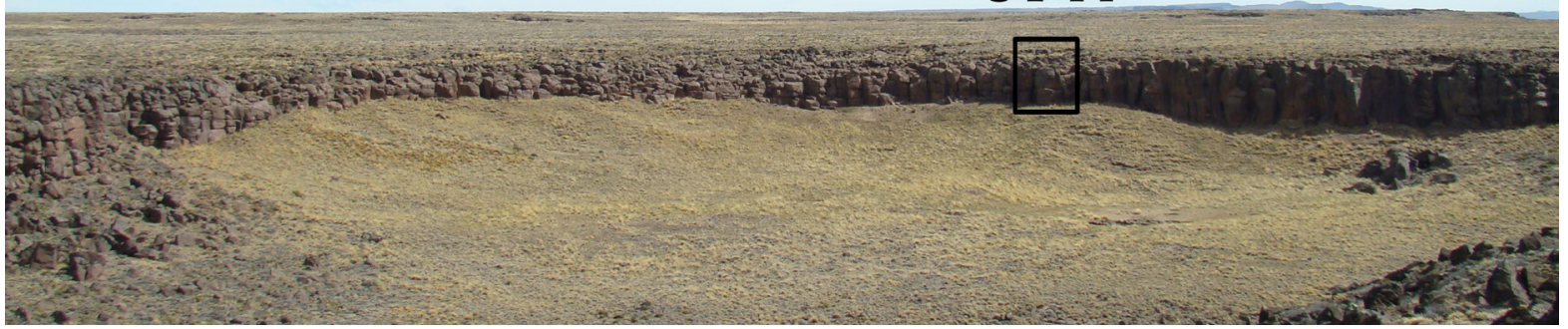

Fig. 1. Localización del sitio CG3 (arriba) y vista del mismo con ubicación de UT14 (abajo).

distinta pátina, un semicírculo, un caótico (picados dispersos) y un rastro de tridígitos compuesto por dos elementos. Se observó una superposición del caótico sobre una de las líneas sinuosas. Asimismo, se registraron los tres grados de pátina de la siguiente manera: un caso de pátina 1 (línea sinuosa), cuatro casos de pátina 2 (líneas sinuosas, semicírculo y caótico) y dos de pátina 3 (tridígitos y línea sinuosa). Al igual que lo observado para el sitio, tentativamente estos indicadores apuntaban a la reutilización de este sector del soporte en distintos momentos.

Dadas las características del registro arqueológico, las actividades que se habrían realizado en el sitio CG3 incluyen tareas de producción y reactivación de artefactos líticos, procesamiento de recursos faunísticos y realización de representaciones rupestres (Cassiodoro et al. 2013).

\section{EL SELLO ARQUEOLÓGICO}

Como se mencionó previamente, la presencia de un sello arqueológico para motivos grabados en Patagonia centro-meridional es una situación sumamente excepcional. La excavación realizada por debajo de la UT14 del sitio CG3 permitió descubrir un sector de la pared con representaciones rupestres que se encontraba enterrado (Figs. 2 y 3).

En este sector se reconoció la presencia de un conjunto de grabados que se continúan desde la superficie de excavación hacia niveles estratigráficos y otros que directamente se ubican en estratigrafía, sumándose tres motivos a los previamente reconocidos (Fig. 3). El primer caso refiere a una línea sinuosa, visible desde aproximadamente $19 \mathrm{~cm}$ por sobre la superficie 


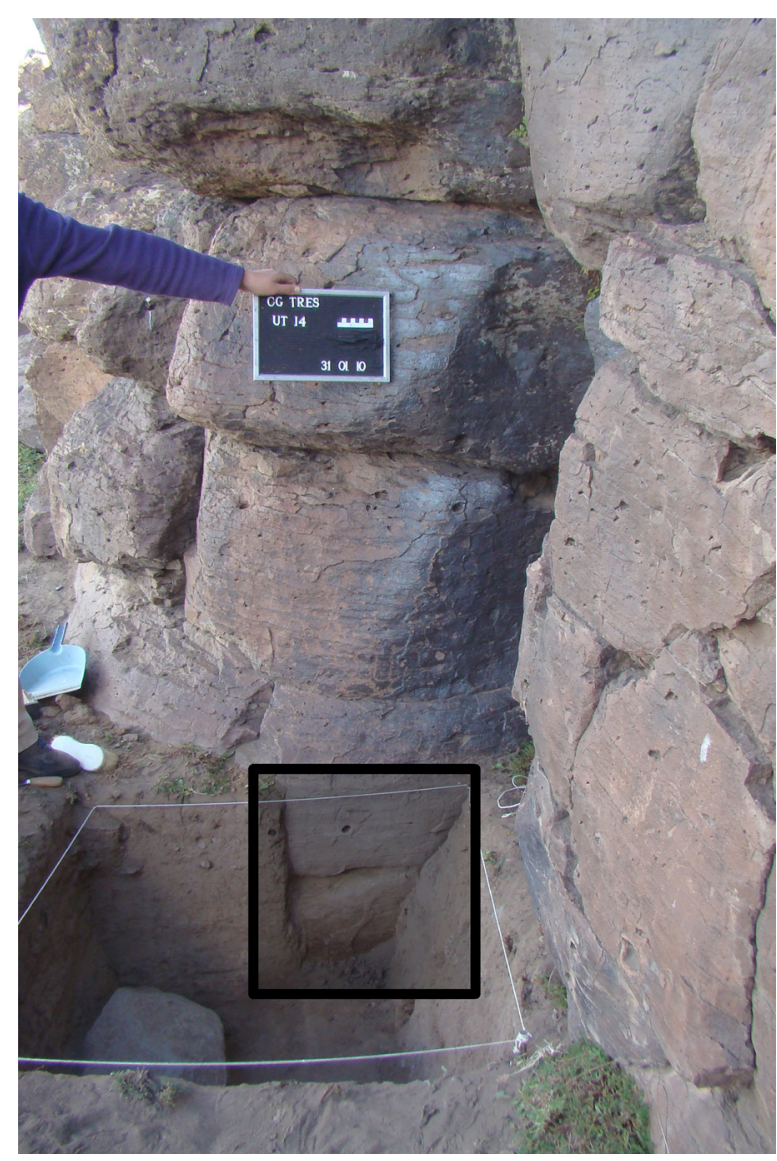

Fig. 2. Excavación en la UT14 del sitio CG3, indicando sector con grabados que se encontraba tapado por sedimentos.

actual del suelo hasta alcanzar una profundidad de $5 \mathrm{~cm}$, ubicándose ya en el nivel 1. Por su parte, el segundo caso está compuesto por tres motivos ubicados completamente en estratigrafía: un círculo unido a una línea curva, una línea sinuosa y un tridígito. Los tres motivos fueron picados y no presentan pátina al igual que el resto del soporte donde se ubican. Se entiende que el proceso de formación de pátina en este sector de la roca fue diferente a lo observado en los restantes paredones del sitio, principalmente en función de haber estado sepultado por sedimentos. El primero de los motivos registrados en la excavación se extiende desde el nivel 2 al nivel 4; el segundo ocupa los niveles 2 y 3 ; y finalmente, el tercero se localiza casi enteramente en el nivel 4. De esta forma, la presencia de grabados en estratigrafía se concentra en los primeros cuatro niveles de la excavación planteada en la UT14, alcanzando los $21 \mathrm{~cm}$ desde la superficie actual. Los motivos que se encontraban sepultados presentan características similares a aquellos registrados en otros sectores del soporte. De esta manera, se evidencia la misma técnica de ejecución así como semejantes tipos de motivos y diseños.

En relación con la evidencia lítica registrada en estos cuatro niveles, se destaca la presencia de gran cantidad de desechos de talla de obsidiana $y$, en cuanto a los artefactos formatizados, un predominio de raspadores de obsidiana y sílice. En particular, en el nivel 1 se recuperaron tres

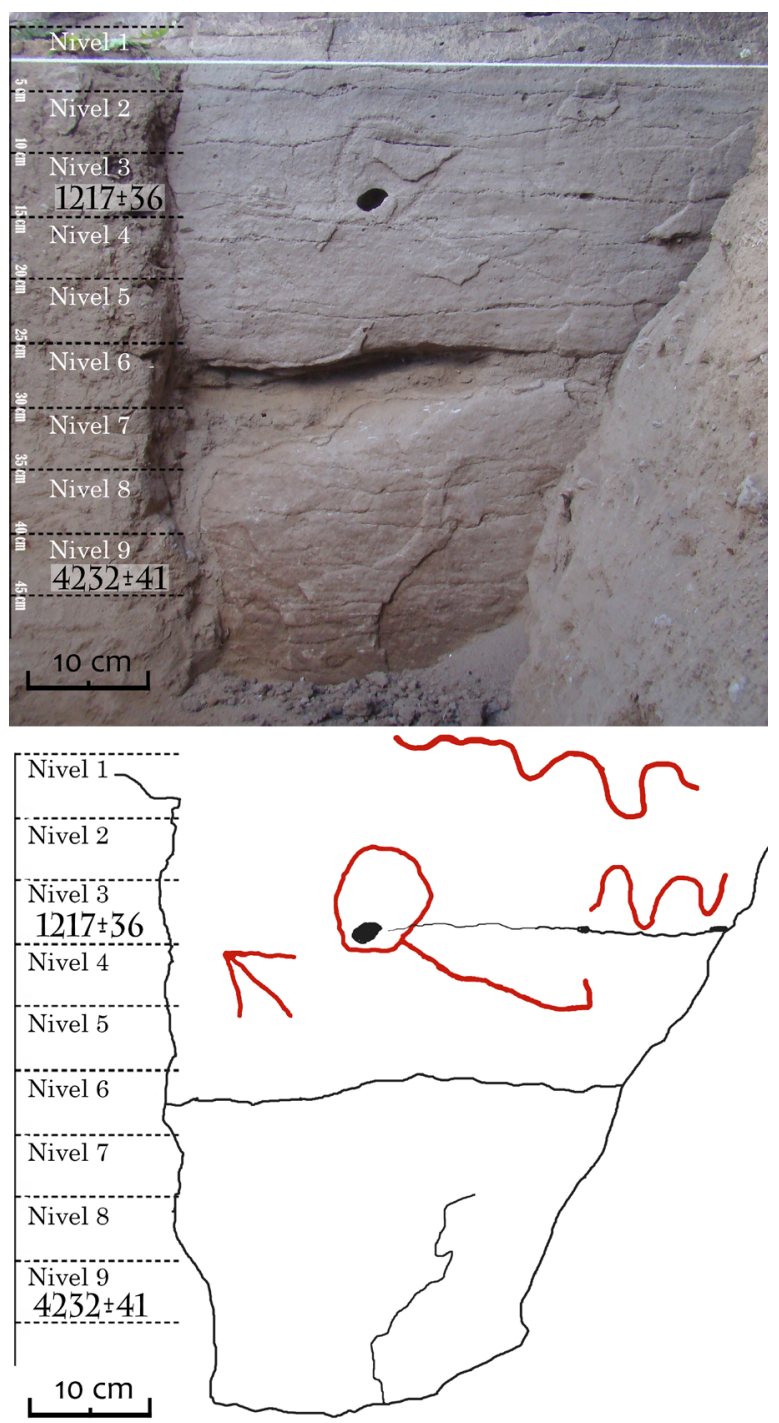

Fig. 3. Detalle de niveles estratigráficos y motivos descubiertos por excavación, con la ubicación de los fechados obtenidos. Izquierda: Foto original, Derecha: Calco digital. 
puntas de proyectil (una entera, un fragmento de limbo y un fragmento de pedúnculo) asignables a diseños triangulares con pedúnculo diferenciado. Cabe mencionar que los dos pedúnculos registrados tienen anchos diferentes (7 y $13 \mathrm{~mm}$ ), potencialmente vinculados con distintos medios de propulsión. Asimismo, puntas con diseños similares y pedúnculos menores a $10 \mathrm{~mm}$ fueron contextualizadas en 380+40 años AP en la cuenca del lago Salitroso (García Guraieb et al. 2007). En el nivel 2 se recuperaron otras tres puntas de proyectil con pedúnculos mayores a $10 \mathrm{~mm}$. En los niveles 2 y 3 se ha recuperado un lito modificado por uso y un pequeño guijarro que podrían haber funcionado como herramientas para la confección de grabados rupestres. Finalmente, en el nivel 4 fue recuperada una única punta de proyectil en sílice con diseño y dimensiones similares a las registradas en el nivel 2. Por su parte, se destaca que uno de los fechados obtenidos de esta excavación procede del nivel 3 y arrojó una cronología de 1.217士36 años AP (Cassiodoro et al. 2013). Esta es la datación que permite establecer una fecha mínima o ante quem para la ejecución de los grabados en estratigrafía.

Siguiendo con las características tecnológicas del sitio, es de destacar que en el nivel 5 se ha recuperado un fragmento de pedúnculo y una punta triangular apedunculada, cuyo diseño ha sido vinculado con ocupaciones del Holoceno medio y temprano (Aschero et al. 2005). Esto enfatiza aún más la variabilidad morfológica de las puntas de proyectil recuperadas en la excavación de la UT14.

Por su parte, los niveles inferiores $(6$ a 21) presentan una menor frecuencia de material lítico, particularmente de artefactos formatizados. Dentro de los mismos, se destacan los raspadores y la ausencia de piezas bifaciales, específicamente de puntas de proyectil. A su vez, se evidencia una mayor presencia de desechos de talla en rocas silíceas. Las cronologías para estos niveles son de $4.232 \pm 41$ años AP (nivel 9) y $4.764+47$ años AP (nivel 15) (Cassiodoro et al. 2013).

\section{DISCUSIÓN Y CONCLUSIÓN}

El sello arqueológico sobre grabados registrado en el sitio CG3 es de características únicas en Patagonia centro-meridional y la información que brinda permite discutir distintos aspectos. En primer lugar, constituye un importante aporte a la discusión sobre la cronología de estos motivos al asignar una fecha mínima de 1.200 años AP para las representaciones descubiertas por la excavación. Esto es coherente con las características de la tecnología lítica presente en esas capas. Sin embargo, no se puede descartar que los motivos hayan sido ejecutados en momentos previos. En ese sentido, es muy interesante el hallazgo en el nivel 5 de una punta de proyectil con diseño asignable al Holoceno medio y temprano, así como las cronologías absolutas entre 4.000 y 5.000 años AP para niveles inferiores.

En una escala de sitio, desde el registro tecnológico las actividades que se habrían realizado en CG3 incluyen tareas de producción y reactivación de artefactos líticos y de procesamiento de recursos faunísticos. La existencia de variabilidad en la estructura artefactual en los distintos niveles estratigráficos apuntaría a un énfasis diferencial de las mismas a lo largo del Holoceno (Cassiodoro et al. 2013). Por su parte, la realización de representaciones rupestres habría sido otra de las actividades efectuadas en CG3. Como se detalló en otro apartado, los indicadores disponibles sugieren varios momentos de ejecución de los motivos (Re, 2010; Re \& Guichón, 2013). La cronología asignada a los nuevos grabados de la UT14 complementa y permite seguir profundizando en la caracterización de la secuencia de ejecución de los mismos y de las ocupaciones en general, ya que se observan numerosas semejanzas (técnica de producción, tipos de motivos y diseños) con los grabados localizados en otros sectores del soporte.

De esta manera, el conjunto de evidencias de CG3 (distintos grados de pátina, superposiciones entre motivos, diseños de algunos grabados, morfología de puntas de proyectil, presencia de cerámica, fechados absolutos y el sello arqueológico descripto) apunta a una redundancia en la ocupación de este espacio a lo largo de un período de tiempo prolongado.

Por otra parte, si se amplía la escala espacial, el dato aquí presentado se suma a los trabajos que se vienen desarrollando respecto a las tendencias temporales en las representaciones rupestres de las mesetas altas del centro-oeste de Santa Cruz (Re, 2010; Re \& Guichón, 2014, entre otros). En 
ellos se considera la presencia de varios momentos de ejecución de los grabados en esas áreas, así como una cronología tanto del Holoceno medio como tardío. Siguiendo estas propuestas, motivos como las líneas sinuosas y los círculos con línea curva habrían sido ejecutados a lo largo de toda la secuencia, mientras que los tridígitos podrían datar del Holoceno tardío (tanto inicial como final). El sello arqueológico de la UT14, junto con las evidencias presentes en la estratigrafía, sugiere una cronología de los motivos aquí discutidos acotada al Holoceno medio y al Holoceno tardío inicial.

Al mismo tiempo, los grabados en estratigrafía presentados son un aporte más para entender el papel que habrían cumplido las mesetas altas en el proceso de poblamiento humano de la región. En particular, dan cuenta de su rol en la circulación de información mediante representaciones rupestres desde al menos 1.200 años AP, sumándose a las evidencias ya disponibles sobre su uso recurrente. Para concluir, en términos metodológicos, se resalta la importancia de efectuar excavaciones contiguas a soportes con grabados no sólo para contribuir a los modelos de poblamiento planteados (Goñi 2010), sino también con el fin de establecer cronologías de las representaciones rupestres.

\section{AGRADECIMIENTOS}

Agradecemos a todos aquellos colegas $y$ estudiantes que colaboraron en las tareas de campo. Asimismo, las investigaciones no habrian sido posibles sin la asistencia en el campo de Chaly Olivero y su esposa Marta, los hermanos Bolke, flía. Martinez de Sanzo y flía. Smart. Los trabajos contaron con el apoyo de la empresa Goldcorp y de la Asociación Identidad y con los subsidios PICT 2012-1352, PICT 2010-1389, PICT 2013-1965 y UBACYT 2014-2017 $\mathrm{N}^{\circ}$ 20020130100293BA. Agradecemos por último los oportunos comentarios de los evaluadores.

\section{REFERENCIAS CITADAS}

Aschero, C., Goñi, R., Civalero, M. T., Molinari, R., Espinosa, S., Guráieb, G., \& Bellelli, C. (2005). Holocenic Park: Arqueología del Parque Nacional Perito Moreno (PNPM). Anales de la Administración de Parques
Nacionales, XVII, 71-119.

Carden, N. (2008). Imágenes a través del tiempo. Arte rupestre y construcción social del paisaje en la Meseta Central de Santa Cruz. Buenos Aires: Sociedad Argentina de Antropología

Cassiodoro, G., Flores Coni, J., \& Dellepiane, J. (2013). Cronología y asentamiento en la Meseta del Guitarra (Santa Cruz): el sitio Cañadón Guitarra 3. En F. Zangrando, R. Barberena, A. Gil, G. Neme, M. Giardina, L. Luna, C. Otaola, L. Paulides, L. Salgán, \& A. Tivoli (Eds.), Tendencias Teórico-Metodológicas y Casos de Estudio en la Arqueología de Patagonia (pp. 297-306). Mendoza: Museo de Historia Natural de San Rafael.

Crivelli Montero, E. (2006). Frecuencia de creación de sitios de arte rupestre en la cuenca media y superior del río Limay (noroeste patagónico). En D. Fiore, \& M. Podestá (Eds.), Tramas en la piedra. Producción y usos del arte rupestre (pp. 63-74). Buenos Aires: World Archaeological Congress, Sociedad Argentina de Antropología y Asociación Amigos del Instituto Nacional de Antropología.

Durán, V. (1983-85). Arte rupestre de los cazadores patagónicos en "El Verano", área de La Martita, Departamento Magallanes, Provincia de Santa Cruz. Anales de Arqueología y Etnología, 43-75

García Guráieb, S., Goñi, R., \& Bosio, L. (2007). Lesiones traumáticas en un entierro del lago Salitroso (Santa Cruz, Argentina) En F. Morello, M. Martinic, A. Prieto, \& G. Bahamonde (Eds.), Arqueología de FuegoPatagonia. Levantando piedras, desenterrando huesos...y develando arcanos (pp. 375-380). Punta Arenas: CEQUA.

Goñi, R. (2010). Cambio climático y poblamiento humano durante el Holoceno tardío en Patagonia Meridional. Una perspectiva arqueológica. Tesis de doctorado. Universidad de Buenos Aires, Facultad de Filosofía y Letras, Buenos Aires. MS.

Goñi, R., Cassiodoro, G., Re, A., Guichón, F., Flores Coni, J., \& Dellepiane, J. (2010). Arqueología de la Meseta del Lago Guitarra (Santa Cruz). En R. Bárcena \& H. Chiavazza (Eds.), Arqueología Argentina en el Bicentenario de la Revolución de Mayo, XVII Congreso Nacional de Arqueología Argentina (pp. 1923-1928). Mendoza: Zeta Editores.Gradin, C. (1973). El Alero de las Manos Pintadas (Las Pulgas, Provincia de Chubut, Argentina). Bolletino del Centro Camuno di Studi Preistorici, X, 169-207.

Gradin, C. (1983). El arte rupestre de la cuenca del río Pinturas, 
Provincia de Santa Cruz, República Argentina. ArsPraehistorica, II, 87-149.

Gradin, C. (2003). Grabados de la Ea. "La Flecha". Gobernador Gregores-Provincia de Santa Cruz. En A. Aguerre (Ed.), Arqueología y paleoambiente en la Patagonia santacruceña argentina (pp. 121-137). Buenos Aires: Talleres Gráficos Nuevo Offset.

Gradin, C., \& Aschero, C. (1978). Cuatro fechas radiocarbónicas para el Alero del Cañadón de las Manos Pintadas. En Relaciones, XII, 245-248.

Re, A. (2010). Representaciones Rupestres en Mesetas Altas de la Provincia de Santa Cruz. Circulación de Información en Espacios de Uso Estacional. Tesis de doctorado. Universidad de Buenos Aires, Facultad de Filosofía y Letras, Buenos Aires. MS.
Re, A., \& Guichón, F. (2013). Las representaciones rupestres de la meseta del lago Guitarra (provincia de Santa Cruz). En F. Zangrando, R. Barberena, A. Gil, G. Neme, M. Giardina, L. Luna, C. Otaola, L. Paulides, L. Salgán, \& A. Tivoli (Eds.), Tendencias Teórico-Metodológicas y Casos de Estudio en la Arqueología de Patagonia (pp. 495-504). Mendoza: Museo de Historia Natural de San Rafael.

Re, A., \& Guichón, F. (2014). Tendencias temporales en los grabados de mesetas altas de Santa Cruz. En IX Jornadas de Arqueología de la Patagonia. Libro de Resúmenes (pp. 52). Coyhaique: CIEP.

Schobinger, J., \& Gradin, C. (1985). Arte rupestre de la Argentina. Cazadores de la Patagonia y agricultores andinos. Madrid: Encuentro Ediciones. 